\title{
Nuclear Pore Protein p62 Autoantibodies in Systemic Lupus Erythematosus
}

\author{
Doris M. Kraemer ${ }^{*}, 1$ and Hans-Peter Tony ${ }^{2}$ \\ ${ }^{I}$ Queen's Cancer Centre, Hull, UK \\ ${ }^{2}$ Medizinische Klinik and Poliklinik II, University of Wuerzburg, Germany
}

\begin{abstract}
Systemic lupus erythematosus (SLE) is a systemic autoimmune disease which is classically characterised by a variety of autoantibodies to deoxyribonucleic acid (DNA), ribonucleic acid (RNA), other nuclear and cytoplasmic antigens. Recently several novel autoantibodies against a variety of specific nuclear pore proteins have been described, including the nucleoporin p62. In this paper we evaluate anti-nucleoporin p62 antibodies by western blot analysis in 25 systemic lupus erythematosus patients. Six patients showed antibodies directed against nucleoporin p62. Our data indicate that p62 antibodies could be a useful additional marker in SLE.
\end{abstract}

Keywords: Systemic lupus erythematosus, autoantibodies, nucleoporin p62.

\section{INTRODUCTION}

Systemic lupus erythematosus is a systemic autoimmune disease with diverse clinical manifestations which are often complex and occur as a result of inflammation in target organs. The revised criteria of the American College of Rheumatology for the classification of SLE incorporate photosensitivity, arthritis, serositis, neurological disorders including seizures and psychosis, renal impairment, haematological disorders and impairment of the lungs, heart and intestine [1]. SLE is serologically defined by a variety of autoantibodies including anti-DNA, anti-phospholipid, antiSm and other antinuclear antibodies.

Due to the substantial progress in elucidation of the structure of the nuclear membrane and pore complex, recently novel autoantigens localised within the nucleus and the nuclear envelope have been investigated in more detail. Enarson et al. [2] differentiate the nuclear envelope (NE) into five regions, the outer nuclear membrane (ONM), an inter membrane space, the inner nuclear membrane (INM), the underlying nuclear lamina and the nuclear pore complex (NPC). Autoantibodies against the nuclear lamina (including lamins $\mathrm{A}, \mathrm{B}$ and $\mathrm{C}$ ), against integral membrane proteins of the INM as the lamin B receptor and lamin-associated polypeptides as well as autoantibodies against nuclear pore proteins (gp210, Nup153, Tpr, p62) have been defined in different autoimmune diseases [2-4].

The nuclear pore complex (NPC) serves as the sole gate between the nucleoplasm and the cytoplasm and contains several different nuclear pore proteins such as nucleoporin p62. Nucleoporin p62 was cloned and sequenced in 1991 [5] and found not to be identical with the cytoplasmic RNAbinding protein p62 which is an autoantigen in human hepatocellular carcinoma [6]. The amino acid sequence of nucleoporin p62 contains phenylalanine- and glycine- rich

\footnotetext{
*Address correspondence to this author at the Haematology Department, Queen Cancer Centre of Oncology and Haematology, Castle Road, Cottingham, HU16 5JQ, UK; Tel: (44) 01482 461291; Fax: (44) 01482
} 607739; E-mail: Doris.Kraemer@hey.nhs.uk
(FG) repeat motifs, which are characteristic for nuclear pore proteins [5]. Nucleoporin p62 is a glycoprotein and probably therefore highly immunogenic [7]. Since the FG-repeat motifs of p62 are flexible and mobile in contrast to nucleoporin $\mathrm{p} 58$ and nucleoporin $\mathrm{p} 54$, which are very similar proteins, this flexible motif might be the reason of strong immunogenicity of p62 [8]. One trial described p62 as an oxalate-binding protein with increased expression in different kidney disorders [9].

Nucleoporins are well described autoantigens in primary biliary cirrhosis where their presence might indicate a more severe course of the disease [10-15]. Anti-nucleoporin antibodies can be also found in systemic connective tissue diseases. For example, in four cases of Sjögren's syndrome [16], four cases of systemic lupus erythematosus $[9,10]$ and one case of Sharp syndrome [17] p62 autoantibodies were identified.

In a previous study, we expressed p62 in three recombinant fusion proteins. Autoantibodies in primary biliary cirrhosis are recognizing the amino terminal fragment of p62 [17]. Since the aminoterminal fragment therefore seems to be the antigen, we used this fragment for further investigations in Lupus erythematosus, to evaluate, if p62 serves as an autoantigen in this disease too. We investigated twenty five patients suffering from the disease. Six of the twenty five patients showed anti-p62 autoantibodies.

\section{MATERIALS AND METHODS}

\section{Collection of Blood Samples}

Serum blood samples of 25 patients suffering from systemic lupus erythematosus were collected. Prior to the trial the project has been approved by the ethical committee in Würzburg/Germany. For each patient, the trial was discussed in detail and the approved consent form was signed prior to participation. Systemic lupus erythematosus was diagnosed according the revised criteria of the American College of Rheumatology for the classification of SLE [1, 18]. All patients were characterized by a prolonged time since diagnosis (13.1 years in average) and had received a 
variety of immunosuppressive drug therapies. 22 patients were female, 3 patients were male. Patient age ranged from 24 years to 64 years. Median age was 41.72 . To quantify the disease we used the SLICC/SDI damage score [19]. As controls we used a 24 year old and a 41 year old healthy woman. Both controls had no antinuclear antibodies or antinative DNA antibodies.

\section{Expression and Purification of p62 Fusion Protein}

The amino terminal domain of $\mathrm{p} 62$ which contains the phenylalanine- and glycine-repeat (FG-repeat) domain (amino acid residue 1 to 329) was expressed using a set of non degenerate oligonucleotide primers (5'-ATGAGCGGC TTTAATTTTGGAGG-3' and 5'-GGTCATGGCGGAGCT GGCAG-3'). Primers contained additional restriction sites for HindIII and XHOI. The corresponding PCR product was inserted between the HindIII- and XHOI restriction sites in
pET21-b vector (Novagen, Madison, Wisconsin) containing a six-histidine tag. The construct was transformed into Escherichia coli BL21 (DE3). P62-His 6 fusion protein was purified under denaturing conditions as described previously [17].

\section{Gel Electrophoresis and Immunoblotting}

P62 fusion protein was analyzed by $15 \%$ sodium dodecyl sulphate-polyacrylamide gel electrophoresis (SDS-PAGE; $10 \mu \mathrm{g}$ of protein/lane) and transferred to Hybond ECL membranes (Amersham, Braunschweig, Germany) at $50 \mathrm{~V}$ for $3 \mathrm{~h}$. After a blocking step with 5\% skimmed milk in phosphate-buffered saline (PBS; $\mathrm{pH}$ 7.4) for $1 \mathrm{~h}$ at room temperature (RT), the Hybond sheets were incubated overnight at $4{ }^{0} \mathrm{C}$ with the control- and patient-sera (diluted $1: 500$ in $5 \%$ milk). Bound antibodies were visualized with horseradish peroxidase-labelled goat anti-human $\operatorname{IgG}$

Table 1. Clinical Disposition and Anti-p62 Antibodies in 25 Patients Suffering from SLE and Two Healthy Controls (C1 and C2)

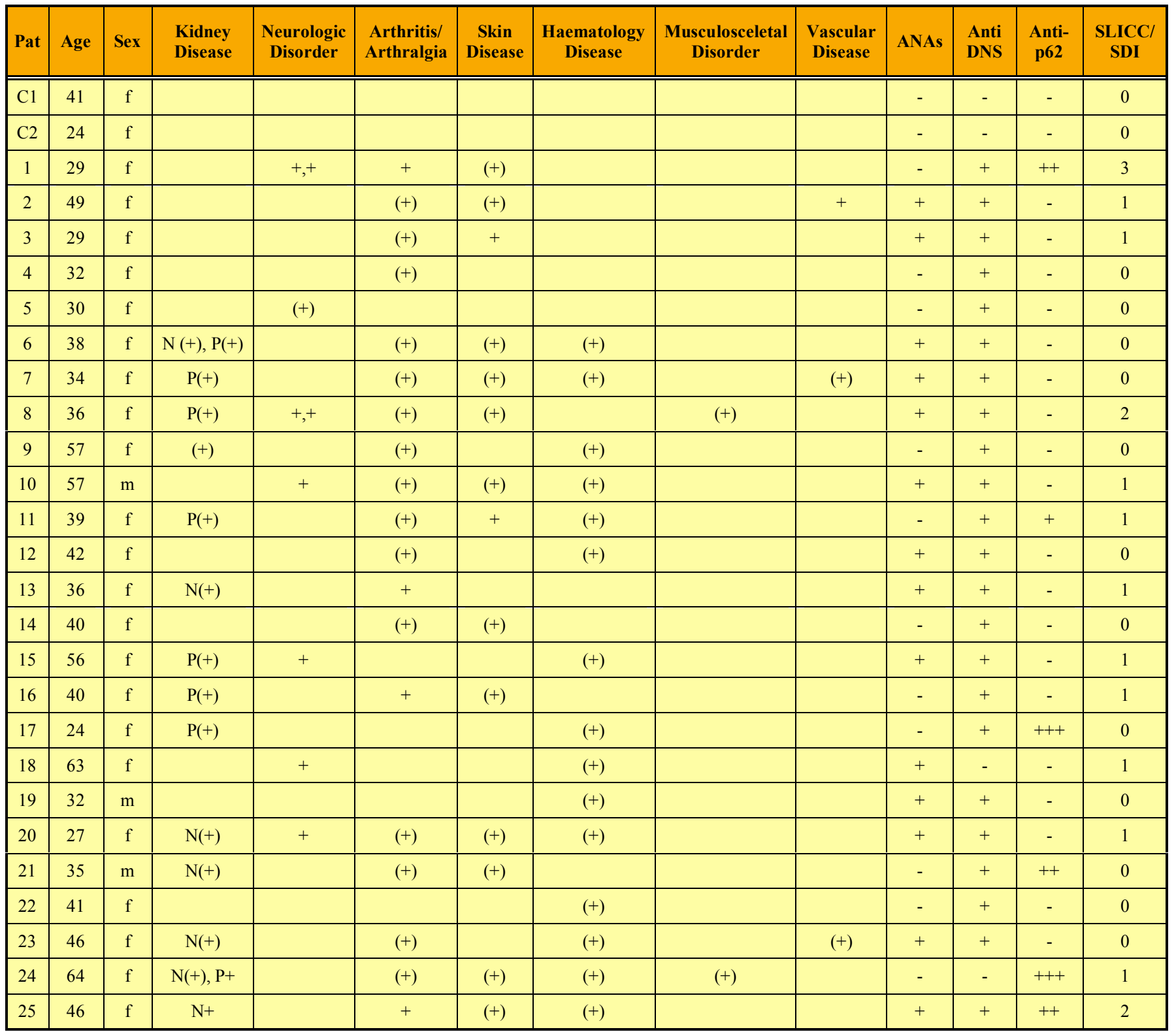

The table shows numbered index of patients (Pat), age, gender, organ disease, p62-autoantibodies and the SLICC/SDI Damage Score for each patient. (+) symptoms without organ damage, + organ damage, $\mathrm{N}$ nephritis, $\mathrm{P}$ proteinuria. 
(Jackson Immunoresearch Laboratories, West Grove, Pa.) diluted 1:4,000 in PBS, including 5\% milk by using enhanced chemiluminescence (Amersham, Braunschweig, Germany).

\section{RESULTS}

To investigate, if SLE is characterized by $\mathrm{p} 62-$ autoantibodies, we expressed the amino terminal fragment of nucleoporin p62 in E. coli. This fragment contains the FGrepeat domains, which are not only the adhesion site for nuclear transport factors, but also serve as the antigenic epitope for p62 autoantibodies [17].

We collected sera of 25 patients suffering from SLE. Data analysis of the patients showed, that seven patients had nephritis during their medical history, six patients were suffering from neurological disorders manifested as seizures. As negative controls we used two healthy women (Table 1).

In 6 of 25 patients (24\%) a distinct band was visualised in the Western Blots corresponding to the binding of p62autoantibodies to immobilised protein (Fig. 1). Five of the six positive patients were female, one patient is male. The median age of positive patients was 39.6. Median time since diagnosis of disease was 11.83 years. Four of our six positive patients had renal disease and one of the anti-p62 positive patients suffered from a severe neurologic disorder characterised by myelitis and paraparesis of both legs.

To quantify severity of disease we used SLICC/SDI damage score [19]. Four of the six patients with anti-p62 were already suffering from organ damage.

\section{DISCUSSION}

SLE is a severe autoimmune disease characterized by antinuclear and anti-DNA antibodies. In this paper we investigated 25 SLE-patients for autoantibodies against nucleoporin p62. Nucleoporin p62 autoantibodies have been extensively studied in primary biliary cirrhosis, but have been rarely described in connective tissue diseases.

In this paper we show for the first time, that nucleoporin p62 serves also as an autoantigen in SLE with a frequency of $24 \%$ of all cases tested. Of the positive cases one was male and five female, indicating that the presence of the antibodies is unrelated to gender. SLE is more frequent in women than in men, but seems to run a more severe course in male patients [20]. To characterize severity of the disease we used the SLICC/SD damage score, since actual disease activity is also dependent on current treatment. 13 of our 25 patients were suffering from at least one site of organ damage. From the anti-p62 patients 4 out of 6 showed significant organ damage. The two patients with no organ damage were a male patient and the youngest patient in our trial, a 24 year old female. One anti-p62 positive patient had extraordinary severe neurological symptoms with myelitis and paraparesis of both legs. Four of the positive patients have severe kidney disease like nephritis, nephrotic syndrome or reduced renal function. Interestingly, it has been investigated, that nucleoporin p62 serves as oxalatebinding protein and plays a role in renal stone formation $[9$, 21]. Nucleoporin p62 expression and urine excretion increase in hyperoxaluria and vary in different kidney disorders. This observation might be due to increased expression of p62 or degradation of the cell membrane by oxalate-induced cell injury [9]. Oxalate, but also other cell toxins might induce apoptosis of cells. Nuclei undergo dramatic changes during apoptosis and anti nuclear pore complex antibodies may evolve as a result of antigenic presentation of proteolytic polypeptide fragments that arise during apoptotic cell death $[22,23]$. This may allow anti-p62 autoantibody formation in autoimmune prone patients with renal injuries.
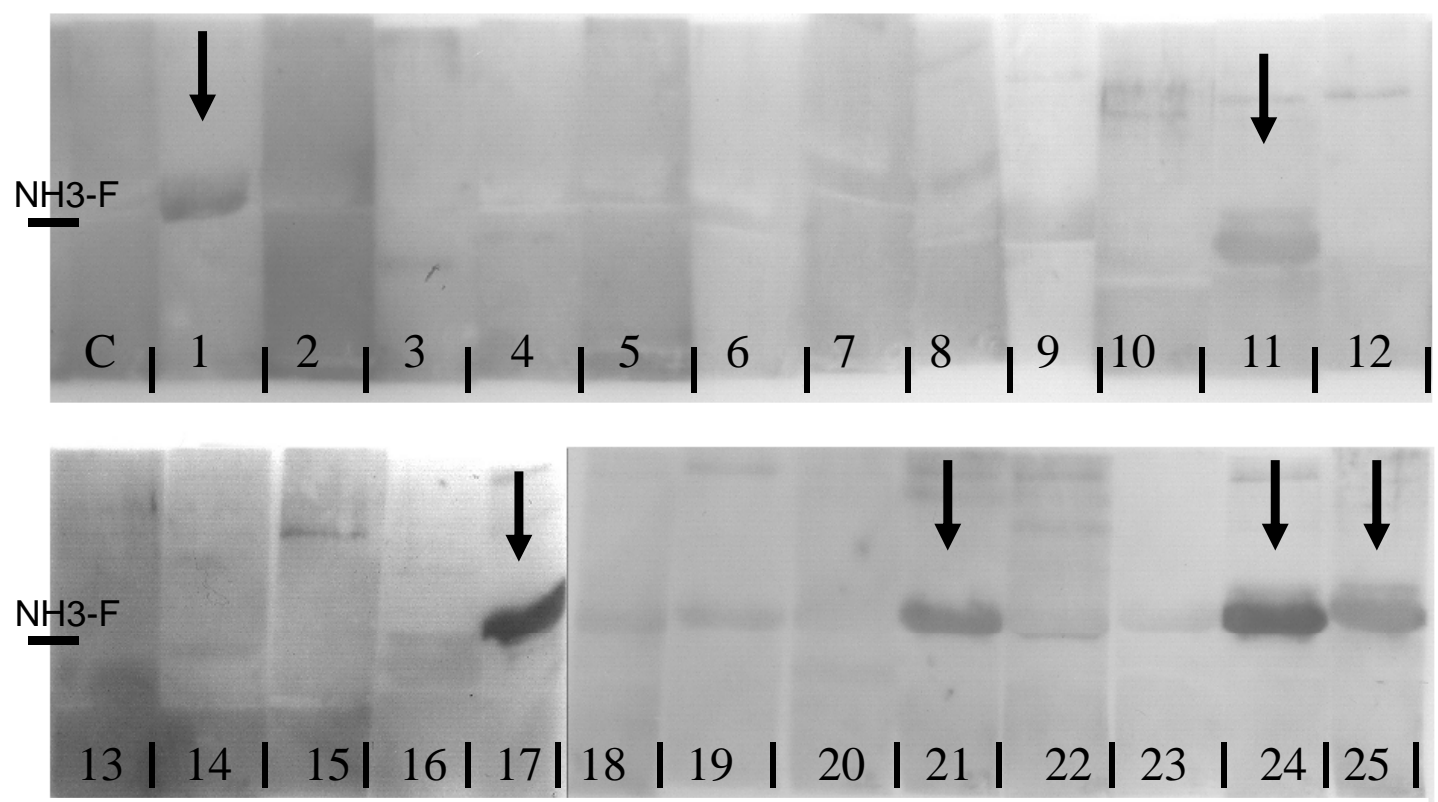

Fig. (1). 15\% SDS PAGE of in E. coli expressed aminoterminal fragment of nucleoporin p62, transferred by Westernblot to nitrocellulose membrane and incubated with patient sera and control sera $(\mathrm{C} 1, \mathrm{C} 2)$. Samples of patients 1, 11, 17, 21, 24 and 25 show positive signals, as indicated by arrows. 
In summary, we show for the first time, that p62 serves as an autoantigen in cases of severe systemic lupus erythematosus. The clinical relevance of this autoantigen has to be evaluated in larger cohort studies and ensured by further methods like ELISA technique.

\section{ACKNOWLEDGEMENTS}

We thank Caroline Abraham and Annette KossKinzinger for excellent technical assistance. Doris Kraemer was supported by a grant of the state of Bavaria (Bayerischer Habilitationsfoerderpreis).

\section{REFERENCES}

[1] Hochberg MC. Updating the American College of Rheumatology revised criteria for the classification of systemic lupus erythematosus. Arthritis Rheum 1997; 40: 1725-34.

[2] Enarson P, Rattner JB, Ou Y, Miyachi K, Horigome T, Fritzler MJ. Autoantigens of the nuclear pore complex. J Mol Med 2004; 82: 423-33.

[3] Nesher G, Margalit R, Ashkenazi YJ. Anti-nuclear envelope antibodies: clinical associations. Semin Arthritis Rheum 2001; 30: 313-20.

[4] Ou Y, Enarson P, Rattner JB, Barr SG, Fritzler MJ. The nuclear pore complex protein $\mathrm{Tpr}$ is a common autoantigen in sera that demonstrate nuclear envelope staining by indirect immunofluorescence. Clin Exp Immunol 2004; 136: 379-87.

[5] Carmo-Fonseca M, Kern H, Hurt EC. Human nucleoporin p62 and the essential yeast nuclear pore protein NSP1 show sequence homology and a similar domain organization. Eur J Cell Biol 1991; 55: $17-30$.

[6] Zhang JY, Chan EKL, Peng XX, Tan EM. A novel cytoplasmic protein with RNA-binding motifs is an autoantigen in human hepatocellular carcinoma. J Exp Med 1999; 189: 1101-10.

[7] Davis LI, Blobel G. Nuclear pore complex contains a family of glycoproteins that includes $\mathrm{p} 62$ : glycosylation through a previously unidentified cellular pathway. Proc Natl Acad Sci USA 1987; 84: 7552-56.

[8] Schwarz-Herion K, Maco B, Sauder U, Fahrenkrog B. Domain topology of the p62 complex within the 3-D architecture of the nuclear pore complex. J Mol Biol 2007; 370: 796-806.

[9] Sivakamasundari P, Kalaiselvi P, Sakthivel R, Selvam R, Varalakshmi P. Nuclear pore complex oxalate binding protein p62: expression in different kidney disorders. Clin Chim Acta 2004; 347: $111-9$
[10] Invernizzi P, Podda M, Battezzati PM, et al. Autoantibodies against nuclear pore complexes are associated with more active and severe liver disease in primary biliary cirrhosis. J Hepatol 2001; 34: 36672 .

[11] Invernizzi P, Selmi C, Ranftler C, Podda M, Wesierska-Gadek J. Antinuclear antibodies in primary biliary cirrhosis. Semin Liver Dis 2005; 25: 298-310.

[12] Wesierska-Gadek J, Hohenuer H, Hitchman E, Penner E. Autoantibodies against nucleoporin p62 constitute a novel marker of primary biliary cirrhosis. Gastroenterology 1996; 110: 840-47.

[13] Wesierska-Gadek J, Klima A, Komina O, Ranftler C, Invernizzi P, Penner E. Characterization of autoantibodies against components of the nuclear pore complexes: high frequency of anti-p62 nucleoporin antibodies. Ann NY Acad Sci 2007; 1109: 519-30.

[14] Miyachi K, Hankins RW, Matsushima H, et al. Profile and clinical significance of anti-nuclear envelope antibodies found in patients with primary biliary cirrhosis: a multicenter study. J Autoimmun 2003; 20: 247-54.

[15] Muratori L, Granito A, Muratori P, Pappas G, Bianchi FB. Antimitochondrial antibodies and other antibodies in primary biliary cirrhosis: diagnostic and prognostic value. Clin Liver Dis 2008; 12: 261-76.

[16] Miyachi K, Shibata M, Onozuka Y, Kikuchi F, Imai N, Horigome T. Primary biliary cirrhosis sera recognize not only gp 210 but also proteins of the p62 complex bearing $\mathrm{N}$-acetylglucosamine residues from rat liver nuclear envelope: anti-p62 complex antibody in PBC. Mol Biol Rep 1996; 23: 227-34.

[17] Kraemer DM, Kraus MR, Kneitz C, Tony HP. Nucleoporin p62 antibodies in a case of mixed connective tissue disease. Clin Diagn Lab Immunol 2003; 10: 329-31.

[18] Fernando MMA, Isenberg, DA. How to monitor SLE in routine clinical practice. Ann Rheum Dis 2005; 64: 524-27.

[19] Stoll T, Sutcliffe N, Mach J, Klaghofer R, Isenberg DA. Analysis of the relationship between disease activity and damage in patients with systemic lupus erythematosus - a 5-yr prospective study. Rheumatology (Oxford) 2004; 43: 1039-44.

[20] Yacoub Wasef SZ. Gender differences in systemic lupus erythematosus. Gend Med 2004; 1: 12-7.

[21] Selvam R, Vijaya R, Sivakamasundari P. Characterisation of nuclear pore complex oxalate binding protein from human kidney. Mol Cell Biochem 2003; 243: 1-8.

[22] Earnshaw WC. Nuclear changes in apoptosis. Curr Opin Cell Biol 1995; 7: 337-43.

[23] Casciola-Rosen LA, Anhalt GJ, Rosen A. DNA-dependent protein kinase is one of a subset of autoantigens specifically cleaved early during apoptosis. J Exp Med 1995; 182: 1625-34.

This is an open access article licensed under the terms of the Creative Commons Attribution Non-Commercial License (http://creativecommons.org/licenses/by-nc/ $3.0 /$ ) which permits unrestricted, non-commercial use, distribution and reproduction in any medium, provided the work is properly cited. 